\title{
Distribución desigual de las oportunidades educativas en el territorio y migración de la matrícula escolar: el caso de la región de Los Lagos (Chile)*
}

\author{
Unequal distribution of educational opportunities in the territory and enrollment migra- \\ tion: the case of the region of Los Lagos (Chile)
}
A distribuição desigual de oportunidades educacionais no território e migração da matrícula escolar: o caso da região de Los Lagos (Chile)

\begin{abstract}
Sebastián Donoso Díaz, ${ }^{\mathrm{a}}$ Óscar Arias Rojas ${ }^{\mathrm{b}}$
anstituto de Investigación y Desarrollo Educacional (IIDE), Universidad de Talca; Centro de Investigaciones Avanzadas en Educación (CONICYT-CIE 05). Telf.: (56-71) 200 251. Correo electrónico: sdonoso@utalca.cl

bInstituto de Investigación y Desarrollo Educacional (IIDE), Universidad de Talca. Telf.: (56-71) 200253.

Correo electrónico: oarias@utalca.cl
\end{abstract}

\begin{abstract}
RESUMEN
Una de las características del sistema escolar chileno actual es la creciente segmentación socioeconómica de sus estudiantes, la cual se agudiza en la última década a la par del crecimiento de la matrícula privada. En el centro de este fenómeno se haya el debate sobre la política de financiamiento del sistema escolar. Más allá de las medidas de vulnerabilidad individual de los estudiantes, en el artículo se discute la necesidad de incorporar aspectos de riesgo educativo asociados a los territorios donde éstos se localizan, y a las relaciones de dependencia entre estos territorios a nivel nacional. Para entender las relaciones entre territorios se analizan los procesos de migración cotidiana de estudiantes entre comunas, profundizando en el caso de la región de Los Lagos. Se concluye con recomendaciones para la política de financiamiento y de gestión de la educación pública, en el contexto del debate de la nueva arquitectura del sistema escolar chileno.
\end{abstract}

Palabras clave: equidad, gobiernos subnacionales, territorio, educación pública, política educativa.

\begin{abstract}
One of the characteristics of the actual Chilean school system is the growing segmentation across socioeconomic groups of students, which has intensified in the last decade along the growth of private schools enrollment. In the heart of this phenomenon has been the policy debate on financing of the school system. Beyond the measures of the student's individual vulnerability, the article discusses the need to incorporate aspects of educational risk related to the territories where the students are located, and the dependency relationships between these areas at a national level. To understand the relationships between regions the daily migration processes of students between districts are analyzed, delving into the case of the Lakes Region. The paper concludes with policy recommendations for the funding policy and the management of public education policy in the context of the discussion of the new architecture of Chilean school system.
\end{abstract}

Key words: equity, subnational government, territory, public education, education policy.

\section{RESUMO}

Uma das características do sistema escolar chileno é a crescente segmentação socioeconômica de seus estudantes, a qual se intensificou na última década juntamente com o crescimento da matrícula privada. No centro de este fenômeno se dá o debate sobre a política de financiamento do sistema escolar. Além das medidas de vulnerabilidade individual dos estudantes, discute-se a necessidade de incorporar os aspectos de risco educativo associados aos territórios onde os estudantes se localizam e as relações de dependência entre essas áreas em nível nacional. Para entender as relações entre os territórios são analisados os processos de migração diária dos estudantes entre as menores subdivisões administrativas (comunas), mais precisamente no que diz respeito à Região de Los Lagos. Conclui-se com recomendações 
para a política de financiamento e de gestão da educação pública no contexto da discussão sobre a nova projeção do sistema escolar chileno.

Palavras chave: equidade, governos subnacionais, território, educação pública, política educativa.

\section{INTRODUCCIÓN}

A partir de la implantación del modelo de subsidio a la demanda de educación en Chile, la participación de la educación pública en el sistema escolar se ha venido reduciendo en forma creciente hasta llegar a una cifra considerable (Cuadro 1): ${ }^{1}$ mientras que en los primeros años del cambio del sistema de vouchers (en 1981), el sector público educaba al $78 \%$ de los estudiantes y cuando se completa la municipalización de la educación pública (1987) este valor desciende a un 60\%. A pesar de que durante los años '90 la participación de la educación pública se estabilizó entre un 54\%-57\% del sistema escolar, desde 1998 se registra nuevamente una fuerte disminución (en su proporción): hacia 2008 sólo el 43\% de los estudiantes del sistema escolar chileno asistían a establecimientos públicos. En forma paralela, el impulso de la institucionalidad pública hacia la educación privada -que se inicia durante con el Gobierno militar y se consolida durante los gobiernos democráticos de los 90- se materializa en una importante expansión de la participación de la educación privada con subvención estatal luego de 1998, representando hacia 2008 casi la mitad de la matrícula del sistema escolar y superando a la educación pública.

A pesar de la importante expansión de la matrícula de la educación privada y de la existencia de una institucionalidad pública en educación abiertamente favorable a la privatización de la educación, la expansión de este tipo de educación no ha sido uniforme. En efecto, durante la última década, el aumento de la matrícula privada -conseguido a expensas de la educación pública- se concentra en estudiantes de ingresos medios (Cuadro 2), de modo que se ha descrito en los últimos años un proceso de segmentación socioeconómica de los establecimientos educativos (a la par de la expansión del sector privado subvencionado por el Estado), en donde los establecimientos municipales concentran crecientemente a la población de menores recursos y mayores costos asociados, mientras que los estudiantes con mejores condiciones de vida se enrolan en establecimientos privados.

Atendiendo al hecho que las interpretaciones de este proceso van desde considerarlo como algo inherente a una mercantilización de la educación, impulsada con fines de instrumentalización política (Redondo, 2005, Oliva, 2008), hasta verlo más bien como resultado de una deficiente implementación del sistema de vouchers que debe ser perfeccionada en el marco de los mismos principios de orientación actuales (Sapelli, 2002), resulta sintomático que en los 30 años de aplicación en Chile de un sistema de estímulo a la competencia y a los sostenedores de establecimientos privados, no exista evidencia concluyente respecto de las ventajas de la educación privada por sobre la pública (Donoso, 2006). Esto debería resultar particularmente embarazoso para los sostenedores privados, precisamente debido a las ventajas que tienen respecto de los sostenedores públicos (municipalidades): posibilidad de lucrar con recursos públicos, de realizar cobros adicionales a las familias (a través del Financiamiento Compartido), de seleccionar estudiantes, de

Todos los cuadros y figuras en Anexo. 
localizar sus establecimientos con total independencia y con bajos requisitos de apertura o funcionamiento, de tener autonomía en la gestión, de administrar recursos públicos (subvención) con criterios privados, y ausencia de responsabilidad respecto de asegurar el derecho a una educación de calidad.

Las dificultades de los expertos para determinar la ventaja de un tipo de escuelas por sobre otro, así como la complejidad de los criterios de método para realizar este tipo de comparaciones $-\mathrm{y}$ validar ciertas investigaciones por sobre otras-, contrastan con la toma de decisiones de los estudiantes chilenos (y sus familias) en la última década: éstos, a pesar de no contar con información empírica concluyente de parte de la comunidad científica sobre la bondad de los establecimientos privados, han orientado decididamente su elección de escuelas hacia este sector -al menos aquellos estudiantes que tienen un nivel de riesgo lo suficientemente bajo como para ser aceptados en los establecimientos particulares subvencionados.

La discusión sobre la política de financiamiento del sistema escolar está en el centro del debate en torno a segmentación de estudiantes y generación de valor agregado por parte de las escuelas (Sapelli, 2002). La revisión de la política de financiamiento se hace necesaria particularmente por los efectos que puede tener en el aumento general de la eficiencia y de la equidad del sistema escolar, más allá de la diferencia de resultados entre escuelas públicas y privadas. Uno de los logros recientes de este debate ha sido la promulgación de la Ley de Subvención Escolar Preferencial (Ley SEP) (Chile, 2008), que a pesar de sus vacíos o limitaciones, ha representado un avance en términos de reconocer algunos de los factores que inciden en la inequidad del sistema escolar.

En este sentido, el perfeccionamiento de la política de financiamiento de las escuelas chilenas debe considerar aspectos históricos y culturales propios del contexto donde se desarrollará, de lo contrario se corre el riesgo de que, como sucede con el sistema actual, existan incentivos para que las diferencias de resultados entre establecimientos públicos y privados confundan la capacidad de producir valor agregado con la capacidad de seleccionar estudiantes (Hsieh y Urquiola, 2006). Estos aspectos de idiosincrasia no sólo deben referirse a las características del sistema educativo (por ejemplo, la importancia del sector privado, la estructura de financiamiento, las preferencias de los estudiantes y sus familias), sino también a las características más generales de los territorios a los que se remiten dichos sistemas.

El análisis de la situación de los diferentes entes encargados de administrar la educación pública en Chile (las municipalidades) muestra importantes diferencias en los desafíos que enfrenta su gestión (Donoso y Arias, 2011). Mientras que la realidad de más del $60 \%$ de las comunas (Cuadro 3) se desarrolla en contextos de baja población, alta ruralidad y alta dependencia de fondos externos (Grupos 1, 2 y 3), sólo el 5\% de las comunas se enfrenta a condiciones de alta población y urbanización (Grupo 6). Estas condiciones influyen en las características del sistema escolar a nivel local: las comunas más pequeñas y rurales tienen menos estudiantes por establecimiento y por docente, y sus sistemas de educación pública representan una carga presupuestaria importante para sus comunas. Los efectos de la dispersión de la población y el aumento de los costos fijos en educación aparentemente han sido considerados en el conjunto del aporte por subvención estatal, apreciándose aportes diferenciados en los grupos de comunas. Sin embargo, el comportamiento del aporte municipal en los grupos de comunas y la baja participación de sostenedores privados en las comunas más rurales y pequeñas indican 
que este carácter "progresivo" de la subvención escolar (según población y ruralidad) es aún claramente insuficiente.

Los indicadores usuales para caracterizar la educabilidad de la población (el riesgo educativo) se relacionan con las condiciones del entorno de los niños y jóvenes que aseguran un desarrollo cognitivo adecuado a las exigencias escolares, el que depende principalmente de la estimulación afectiva, la nutrición y las condiciones sanitarias (Tedesco y López, 2002): ingreso del hogar, escolaridad de los padres, aspectos relativos al estatus ocupacional y situación laboral de los padres. Estos indicadores son esencialmente los mismos que se ocupan para determinar el nivel socioeconómico de los estudiantes, ${ }^{2}$ la vulnerabilidad escolar de estudiantes y escuelas, y la gradualidad de la subvención escolar:

La calidad de alumno prioritario será determinada anualmente por el Ministerio de Educación [...] de acuerdo a los siguientes criterios: a) Los alumnos cuya familia pertenezca al Sistema Chile Solidario $[. .$.$] ; b) Los alumnos [...] caracterizados dentro del tercio más vulnerable de$ las familias que cuenten con caracterización socioeconómica de su hogar[...]; c) Los [...] [alumnos cuyos] padres o apoderados hubieren sido clasificados en el tramo A del Fondo Nacional de Salud; d) Tratándose de alumnos [...] que no hayan quedado comprendidos en las letras anteriores, para [...] su calificación como prioritarios, se considerará, [...] los ingresos familiares del hogar, la escolaridad de la madre y, en su defecto, la del padre o apoderado [...], y la condición de ruralidad de su hogar y el grado de pobreza de la comuna donde resida el referido alumno [...] (Chile, 2008).

Estos indicadores remiten fundamentalmente a condiciones de vulnerabilidad (riesgo) individual o familiar, dejando de lado en gran medida los aspectos estructurales que determinan riesgo en la población: en este caso, el riesgo asociado a los procesos de enseñanza-aprendizaje. En el caso de la Ley SEP se incorporan factores como la localización rural del hogar o el nivel de pobreza de la comuna, pero sólo como indicadores de riesgo de segunda opción ante estudiantes que no hayan sido evaluados aún según los mecanismos de caracterización socioeconómica (basados en mediciones individuales y familiares de vulnerabilidad). Los aspectos estructurales involucrados en las situaciones de riesgo socioeducativo y pobreza se asocian a las condiciones de dependencia y falta de autonomía -así como de competencias para el uso de la autonomía personal y comunitaria. Estas condiciones no son captadas por medidas individuales ya que remiten a relaciones de dependencia (o desigualdad) entre individuos, comunidades y territorios: no es lo mismo ubicarse en el quintil de menores ingresos en una comuna del Grupo 1 (Cuadro 3) que en una comuna perteneciente al Grupo 6: mientras en la primera la condición de pobreza afecta a casi el doble de la población que en la segunda, las oportunidades educativas que se les ofrecen (participación de la educación pública), los recursos disponibles para apoyarlos desde el nivel local (dependencia del FCM), y en definitiva las condiciones de acceso a derechos sociales como el trabajo, la vivienda o la salud son diametralmente opuestos. De este modo, es evidente que además de las caracterizaciones individuales de riesgo que debe considerar el subsidio educativo, la política de financiamiento de la

2 La prueba SIMCE incorpora una clasificación socioeconómica de los estudiantes que rinden la prueba que se basa en tres indicadores: escolaridad de los padres, ingreso del hogar y nivel de vulnerabilidad del establecimiento (que entrega JUNAEB a partir de la aplicación de encuestas a estudiantes y el cruce con información de los servicios públicos). 
educación pública debería incorporar algunos elementos que den cuenta de las situaciones estructurales o de dependencia que inciden en la vulnerabilidad escolar.

La migración de personas es acaso el factor más distintivo de las situaciones de desarrollo desigual y dependencia entre territorios. Ya sea entre territorios a nivel nacional (Rodríguez y González, 2006) o internacional (Cuevas y Vázquez, 2009) la migración aparece asociada a la búsqueda de mejores condiciones de vida, a inequidades en el desarrollo y a relaciones de dependencia que involucran a individuos (migrantes y no migrantes) y a los territorios de origen y destino -en el caso de estos últimos, por ejemplo dependencia asociada al uso de recursos, a ventajas comparativas por mayor peso demográfico, dinamismo productivo, entre otras.

Con el fin de indagar en la dimensión relacional de la vulnerabilidad escolar de estudiantes y familias, a continuación se analiza el fenómeno de la migración intercomunal de estudiantes en el sistema escolar chileno. A través del análisis de las configuraciones locales de la migración de estudiantes, se espera poder aportar elementos para la discusión de una política de financiamiento que incorpore la dimensión territorial del riesgo escolar.

\section{ASPECTOS METODOLÓGICOS}

El análisis de migración de matrícula se realizó con información secundaria recogida de la encuesta chilena de hogares (CASEN) (MIDEPLAN, 2006) y del directorio de establecimientos y estudiantes del Ministerio de Educación de Chile (MINEDUC, 2007a, 2007b), correspondiente al año 2006. Para la caracterización de regiones y comunas se utilizó la información del Sistema Nacional de Información Municipal del año 2007 (SINIM, 2007). Se entiende como "migración intercomunal de estudiantes" la migración cotidiana ("pendular") de estudiantes entre comunas (traslados diarios), considerándose sólo traslados a distancias inferiores a los 300 kilómetros diarios (ida y vuelta). El presente estudio es de corte transversal: esto permite analizar los desplazamientos entre estudiantes dentro de un mismo sistema (municipal o particular subvencionado) y nivel educativo (educación básica o educación media). Su alcance es limitado ya que no puede entregar información sobre los estudiantes que migran entre sistemas educativos (i.e. entre el sistema municipal y el particular subvencionado). A pesar de esta limitación, el análisis permite comprender mejor las variables que inciden en la migración de matrícula en general, y que pueden inferirse relevantes también para la migración entre los sistemas educativos públicos y privados en Chile.

\section{RESULTADOS}

\subsection{MIGRACIÓN DE ESTUDIANTES EN EL SISTEMA ESCOLAR: UNA MIRADA A LAS REGIONES DE CHILE}

En el nivel de educación básica, el promedio de migración de estudiantes a nivel nacional alcanza un $11 \%$ (Cuadro 4), que se explica principalmente por la alta migración de la región de Santiago, que alcanza un 22\% -mientras que en las regiones no supera 7\%. Al comparar el sistema municipal con el particular subvencionado se aprecia que 
la migración en este último duplica la que se aprecia en el sistema público, alcanzando un $16 \%$. Las regiones que muestran mayores niveles de migración en educación básica particular subvencionada corresponden a Santiago (25\%), O’Higgins (14\%), Valparaíso (11\%) y Bío Bío (10\%). La migración en educación básica municipal es menor en todas las regiones, aunque se mantiene la preponderancia de Santiago como región con mayor migración.

La migración de estudiantes tiene un impacto mayor en educación media (Cuadro 5): a nivel nacional, un $31 \%$ de los estudiantes de este nivel migra cotidianamente a un establecimiento fuera de su comuna de origen, lo que triplica lo que sucede en educación básica. También se aprecia en este nivel una mayor migración entre quienes asisten a establecimientos particulares subvencionados (38\%) en comparación a quienes asisten a establecimientos municipales (23\%). La proporción de estudiantes que migran en educación media (considerando educación municipal y educación particular subvencionada) es especialmente notoria en la Región Metropolitana (50\%) y luego en las regiones entre Coquimbo y Los Lagos -además de Tarapacá-, donde alcanza entre un $15 \%$ y un $27 \%$. En las demás regiones la migración tiene un alcance mucho menor.

Las diferencias que se observan entre niveles y tipos de educación pueden explicarse por dos factores principales:

a. Respecto de las diferencias entre educación básica y media, esta última oferta sólo hace pocos años aumentó (2003) su cobertura, mientras que la educación básica alcanzó universalidad hace más tiempo. Esto incide en que la homogeneidad de la oferta sea más elevada que en educación media, donde hay mayor diversidad no sólo por las brechas de calidad al respecto, sino porque hay diferentes currícula (orientación científica humanista o técnico profesional). Por otro lado, padres o apoderados prefieren que sus hijos menores estudien más cerca del hogar (Chumacero et al., 2008).

b. Respecto de la mayor migración que se observa en el sistema particular subvencionado, aparentemente esto se debe a la desigual ubicación de estos establecimientos en el territorio. La educación municipal (pública) tiene el imperativo de dar cumplimiento del derecho a la educación de todos los habitantes del país, lo que implica desplegarse por los diferentes territorios, incluso en aquellos donde los costos de la provisión de servicios educativos son prohibitivos (zonas aisladas o extremas, de baja población o de bajos niveles de educabilidad de la población). Éste no es el caso de la educación particular subvencionada, que no sólo puede seleccionar a sus estudiantes, sino que además puede definir en forma desregulada dónde localizar sus establecimientos, puesto que está dirigida en su mayoría por sostenedores privados con fines de lucro. En este contexto, y dada la baja elasticidad del subsidio actual en educación en relación a estos factores, la probabilidad de encontrar un establecimiento particular subvencionado es mínima en zonas rurales, aisladas o de baja población, de modo que los habitantes de estos territorios -generalmente- deben trasladarse a otras comunas para acceder a este tipo de servicios.

Además de la comparación por sistemas y tipo de educación a nivel nacional, es relevante notar que, si comparamos estos resultados con la diversidad de poblamiento de las regiones (Cuadro 6), se registra la tendencia entre población, densidad y migración de matrícula: las regiones extremas, menos pobladas y menos densas tienen bajos niveles de migración (con la excepción de Tarapacá), los que aumentan a medida que nos desplazamos a las regiones más pobladas y de mayor dispersión de su población -entre las regiones de Coquimbo y Los Lagos- y se hacen máximos en la región de Santiago, la región de 
mayor densidad poblacional. De este modo, se aprecia una relación entre las características de poblamiento de los territorios y la migración de estudiantes que permite señalar tres zonas de migración diferenciada a nivel nacional: a) regiones de escasa migración (Arica y Parinacota, Tarapacá, ${ }^{3}$ Antofagasta, Atacama, Aysén y Magallanes); b) regiones de migración intermedia (Coquimbo, Valparaíso, O`Higgins, Maule, Bío Bío, Araucanía, Los Ríos y Los Lagos); y c) una región de alta migración (Santiago).

La situación de las regiones de migración intermedia es especialmente relevante: estas regiones concentran el 50\% de los estudiantes del sistema escolar, y más del $60 \%$ de toda la matrícula pública chilena (Cuadro 7). Por otro lado, se trata de regiones que, debido a sus patrones de poblamiento, presentan una gran diversidad en sus comunas, de modo que en una misma región pueden encontrarse comunas de variado peso demográfico o ruralidad. Además de esto, la mayor participación municipal de la matrícula en estas regiones da cuenta de la existencia de una población que tiene mayores costos asociados. Dentro de estas regiones resulta de interés indagar en el caso de la región de Los Lagos: se trata de una región de alta población con una alta participación municipal (Cuadro 7) en su sistema escolar, cuyo poblamiento histórico ha consolidado territorios diferenciados (Osorno, Llanquihue, Chiloé, Palena) y en donde puede hallarse un grado importante de diversidad entre comunas. A continuación se analiza la región de Los Lagos como un caso específico de migración de estudiantes, poniendo énfasis en el nivel educacional que presenta mayor migración (educación media).

\subsection{AGRUPACIONES COMUNALES EN EDUCACIÓN EN LA REGIÓN DE LOS LAGOS}

La revisión de las relaciones de migración entre las comunas de la región muestra un protagonismo de las comunas de Osorno, Puerto Montt y -en menor medida- Castro como atractores de matrícula. En educación municipal (Figura 1) se registran menos lazos (pero de mayor intensidad) ${ }^{4}$ en Osorno en relación a Puerto Montt. La proporción de estudiantes que viven en comunas aledañas y migran cotidianamente a Osorno es elevada: con la excepción de Purranque, para el resto de las comunas proveedoras la migración representa sobre un $20 \%$ de sus estudiantes. A diferencia de Osorno, Puerto Montt tiene lazos de atracción de matrícula con más comunas -9 en total-, pero la fortaleza de estos lazos tiende a ser relativamente menor (con la excepción de Cochamó). Castro atrae una proporción importante de estudiantes de las comunas de Puqueldón (52\%), Chonchi (41\%) y Dalcahue (20\%), así como de otras comunas de la provincia de Chiloé. Sin embargo, dada la mayor cercanía de las comunas, se aprecian intercambios importantes de estudiantes entre varias de ellas. Además de Osorno, Puerto Montt y Castro, se aprecia que las comunas de Frutillar y Puerto Varas también aparecen como focos importantes de atracción de matrícula.

La red de migración de estudiantes en educación media particular subvencionada es de mayor densidad que la de educación media municipal (Figura 2): los lazos de migración son más importantes y aparecen más comunas atractoras, lo que es coherente

\footnotetext{
3 De acuerdo al Cuadro 6, la migración de estudiantes en la región de Tarapacá es mayor que el promedio de las regiones extremas, lo que se debe a la relación particular que se forma entre las comunas de Iquique y Alto Hospicio. Sin embargo, el patrón de migración típico de esta región es el de las zonas de migración escasa.

4 En este caso, se entiende como "fortaleza del lazo" la proporción de los estudiantes que viven en la comuna de origen que se trasladan a estudiar a la comuna receptora.
} 
con la mayor migración de estudiantes de la región en este segmento. Además de la centralidad de Osorno, Puerto Montt y Castro, se observa que Río Negro, Purranque, Ancud y Chonchi se convierten en comunas receptoras de estudiantes.

En ambas redes analizadas (municipal y particular subvencionada), las relaciones de migración entre comunas tienden a generar estructuras de anillos o clusters en educación. De esta forma, las comunas de Osorno, Puerto Montt y Castro son el centro de flujos de estudiantes que provienen de comunas aledañas. Esta migración no responde a una política intencionada de asociación entre comunas, como debiese ocurrir si existiesen mecanismos de cooperación eficientes entre los proveedores de educación de los distintos territorios, sino a formas naturales en que la demanda educativa se ha configurado en los territorios. La generación de estas estructuras permite suponer -al mismo tiempo- una oferta diferenciada en el territorio: si la oferta fuera más homogénea (como sucede en educación básica), la migración sería menor. Para entender la dinámica de migración en los anillos de comunas (o clusters), se exploran las relaciones al interior de las dos principales asociaciones naturales de la región, en el sistema de educación media municipal (educación pública).

\subsection{LAS COMUNAS DE PUERTO MONTT Y OSORNO COMO POLOS REGIONALES DE ATRACCIÓN DE ESTUDIANTES}

Al explorar las relaciones entre comunas en el anillo de Puerto Montt (Cuadro 8), se genera un núcleo central compuesto por el eje de comunas "Puerto Montt/ Puerto Varas". Ambas comunas poseen un porcentaje de pobreza similar al promedio del anillo, pero tienen menor dependencia del Fondo Común Municipal (FCM). Puerto Varas es de menor tamaño y tiene una alta migración de estudiantes; sin embargo, éstos no lo hacen principalmente a Puerto Montt, sino a diversas comunas limítrofes (Figura 1). Un factor que podría determinar este tipo de migraciones es la alta proporción de población que vive en zonas rurales o en agrupaciones urbanas dispersas. Más allá de la adscripción a una determinada comuna, la población accedería a las oportunidades educativas presentes en sus territorios naturales, territorios que no siempre coinciden con los límites geográficos y políticos de las comunas y que no han sido objeto de la política pública en educación (dado que la política actual no incorpora este factor de análisis). Por otro lado, la revisión de las comunas del anillo da cuenta de una relación entre lejanía del foco del anillo, mayor dependencia del FCM, mayor ruralidad y mayor participación municipal en educación. A pesar de que los cambios en la proporción de población en situación de pobreza no siguen este patrón, los demás indicadores dan cuenta de un desarrollo desigual del territorio, el que se concentra en la comuna foco de Puerto Montt y desde ahí disminuye en intensidad hacia la periferia. En este sentido, las oportunidades educativas se agrupan en el centro, lo que es coherente con una migración que asume la forma de un anillo jerárquico.

Las comunas de Llanquihue, Frutillar y Los Muermos tienen una población similar, en torno a los 17 mil habitantes, pese lo cual el tamaño de la matrícula municipal en educación media es diferente, relacionándose básicamente con la ruralidad de su población, de modo que Los Muermos (60\% de ruralidad) posee el doble de estudiantes que Llanquihue (20\% de ruralidad). En coherencia con estos resultados, en Los Muermos la migración es menor, y en relación con las comunas de Llanquihue y Frutillar, es mayor 
el impacto de los estudiantes que capta de otras comunas. Es dable pensar que en el contexto de una comuna de mayor ruralidad, el polo de atracción lo constituya el centro urbano más próximo (Los Muermos), mientras que en una comuna de población más urbana, lo constituya un centro urbano de mayor tamaño localizado en otra comuna. En este sentido, la migración aparece como una estrategia para buscar mejores oportunidades educativas en un contexto de distribución desigual de las oportunidades en el territorio.

Como ya señalamos, el anillo en torno a Osorno (Cuadro 9) involucra menos comunas, las que están más cerca entre sí que las del anillo de Puerto Montt. La cercanía puede ser un factor que acentúe la migración desde centros menos poblados: las tres comunas que se ubican a menos de 40 kilómetros de Osorno (San Pablo, San Juan de la Costa, Río Negro) proveen cerca de la mitad de sus estudiantes a la comuna foco del anillo. A mayor distancia la migración de estudiantes disminuye. Un segundo factor que es relevante en este anillo es la existencia de comunas de mayor tamaño a mayor distancia de Osorno, lo que parece relacionarse en forma inversa con la migración de estudiantes: es el caso de la comuna de Purranque -y en menor medida de Puyehue- que tienen más habitantes, dependen menos del FCM y tienen una migración menor (nuevamente, el nivel de pobreza no muestra una relación tan clara con la migración de estudiantes). Estos resultados reproducen lo observado en el anillo en torno a Puerto Montt: existe una racionalidad en la migración que conecta lugares de menor desarrollo con centros urbanos más avanzados (en relación con el territorio circundante), lo que da cuenta de que las oportunidades percibidas por los actores están desigualmente distribuidas en el territorio. Por otro lado, aparentemente no se trata sólo de una migración motivada por la proporción de personas en situación de pobreza presente en los territorios, sino de las distintas capacidades de estos territorios de ofrecer oportunidades educativas a la población -algo que se asocia mejor a un indicador como "dependencia del FCM" que a "proporción de personas en situación de pobreza". Finalmente, también se observa que las comunas más lejanas al foco del anillo pierden y reciben estudiantes, lo que puede relacionarse al efecto de la ruralidad y dispersión de la población en la migración descrita en el anillo en torno a Puerto Montt.

El análisis precedente expone que la posición de las comunas de Puerto Montt y Osorno, como polos de atracción de estudiantes en la región de los Lagos, se asocia a que se trata de comunas de mayor población y autonomía presupuestaria. Estos factores inciden en una oferta más variada en términos de establecimientos y programas. Por otro lado, más allá de las diferencias en la oferta educativa, es dable sostener que los sistemas educativos de estas comunas ejerzan atracción sobre los estudiantes de comunas más pequeñas y rurales debido al carácter "cosmopolita" de estas comunas, junto con tener una mayor oferta educativa. Las ciudades de mayor tamaño también resultan más atractivas debido a su carácter urbano, a diferencia de las comunas aledañas que tienen un componente rural mayor; así, se presenta una tendencia que relaciona ruralidad con alta dependencia del FCM, distancia de los centros urbanos de la región (en el caso analizado, Osorno y Puerto Montt), mayor participación municipal (pública) en educación media y migración de estudiantes. Esta tendencia es la que permite describir anillos de migración entre comunas aledañas.

En este sentido, se puede inferir que la migración escolar corresponde a una estrategia de los estudiantes y sus familias para acceder a mejores oportunidades educativas y de desarrollo personal, en un contexto en donde estas oportunidades no son satisfechas en 
sus comunas de origen. Es decir, en un contexto en donde las oportunidades educativas y de crecimiento personal están centralizadas, donde los estudiantes de zonas más aisladas o de menor desarrollo tienen un acceso discriminatorio a las oportunidades educativas.

Por otro lado, tanto en el caso de Puerto Montt (Cuadro 10) como en el de Osorno (Cuadro 11), a pesar de que los resultados de la educación municipal de las comunas atractoras tienden a ser mejores, esta diferencia se registra en el conjunto de los resultados de las comunas de los anillos, estableciéndose que no hay coherencia entre localización, migración y resultados. Por el contrario, el dato sobre el nivel socioeconómico de los estudiantes que rinden la prueba SIMCE se relaciona con la posición de las comunas en los anillos estudiados. En este sentido, la migración de estudiantes respondería a decisiones de las familias y estudiantes que tienen que ver con elementos que trascienden los resultados de aprendizaje, y que podrían tener que ver con la aspiración a un mejor estatus social o a la cercanía con territorios de mayores oportunidades en términos laborales, culturales. Así, la migración de estudiantes podría estar relacionada con las estrategias más generales que ocupan las familias para asegurar su subsistencia y reproducción en contextos de pobreza y precariedad en el aseguramiento de los derechos sociales básicos.

\section{CONSIDERACIONES FINALES}

Los resultados del análisis de la migración intercomunal de los estudiantes muestran una relación entre estos desplazamientos y los recursos de los estudiantes así como de sus territorios de origen. De este modo, la migración a nivel nacional se configura de acuerdo al nivel de desarrollo productivo y demográfico de los distintos territorios en el país: es máxima en la región de Santiago (especialmente en el Gran Santiago), intermedia en las regiones de la zona central del país y mínima en las regiones extremas. Por otro lado, en el análisis de la región de Los Lagos se percibe como los movimientos de estudiantes entre comunas siguen el patrón de desarrollo regional concentrado en las capitales provinciales -con la excepción de la provincia de Palena, debido a su bajo desarrollo demográfico.

De tal forma, la migración de estudiantes sigue el gradiente de las inequidades y desequilibrios del desarrollo territorial, tanto a nivel nacional como regional, de modo que la migración cotidiana de estudiantes puede considerarse como una estrategia de las familias para enfrentar la desigualdad de oportunidades que les impone el lugar donde viven. De esta manera se puede inferir que los estudiantes (y familias) que tienen más competencias y recursos para enfrentar estas condiciones de inequidad en las oportunidades educativas, migrarán hacia sistemas educativos de comunas más desarrolladas, con mayor y mejor oferta, mientras que quienes estén en condiciones más deprivadas no podrán ampliar su repertorio de oportunidades, permaneciendo en sus comunas de origen. ${ }^{5}$

La constatación de un nivel relativamente importante de migración a nivel subnacional da cuenta de dos limitaciones en la política pública educativa actual: Primero, a nivel de la política de financiamiento, ya que no es capaz de ecualizar las oportunidades educativas en los diversos territorios; y segundo, a nivel de la política de gestión descentralizada

Por otro lado, si estos estudiantes con inferiores condiciones de origen quisieran acceder a establecimientos de comunas de mayor tamaño, probablemente serían filtrados en los procesos de selección de estos establecimientos. 
de la educación pública, ya que no es capaz de abordar las necesidades de política en el nivel agregado subnacional.

Respecto de la política de financiamiento, se hace necesario incorporar los factores asociados al territorio en el cálculo de la subvención escolar, de modo de ajustar a la realidad la relación entre costos y productividad esperada de los establecimientos. En esta dimensión territorial, no basta con incluir los factores relativos al riesgo individual, sino que se hace necesario estimar la posición relativa de los estudiantes en el territorio, de manera de considerar los riesgos que esta situación específica conlleva para su inserción en el proceso de enseñanza aprendizaje. Esto implica considerar distintas modalidades y puntos de equilibrio de eficiencia de acuerdo a la localización de los estudiantes: alumnos por establecimiento, alumnos por docente, gasto por estudiante. Para tal efecto, se debe considerar el objetivo de proveer educación de calidad en condiciones de equidad para todos los estudiantes, un imperativo del derecho a la educación. Este trabajo requiere el desarrollo de tipologías de comunas en el territorio nacional que no solo señalen sus características individuales, sino que además permitan visualizar las relaciones que se generan entre ellas -y de este modo, los territorios "naturales" que describen.

Un mejor cálculo de la subvención debería aumentar la oferta privada en todo el territorio nacional. De no mejorar las condiciones de operación y gestión de la educación pública, el mejor financiamiento generalizado podría significar la reducción de este tipo de educación a su mínima expresión. Ante esto es importante enfocar la política de gestión descentralizada de la educación pública, de modo de saldar las diferencias que tiene con las posibilidades y prácticas de gestión de la educación privada a nivel local y de los establecimientos, generando condiciones que permitan una competencia más equitativa. Conjuntamente, los sostenedores privados tendrían que asumir deberes que aseguren efectivamente que cumplen una función de apoyo en el aseguramiento del derecho a una educación de calidad para todos los estudiantes, al mismo tiempo que los establecimientos públicos dispongan de los recursos y condiciones de gestión adecuados para competir en términos equivalentes con las escuelas privadas.

No obstante, la educación pública tiene un rol en el desarrollo regional y territorial que no es posible exigir a los proveedores privados. Mientras que la educación privada apela a una relación mercantil e individualista entre escuela y estudiante, la educación pública trasciende este aspecto y tiene la exigencia social de constituirse en un aporte al desarrollo en el nivel nacional y subnacional. Mientras que el aporte de las escuelas particulares opera en un nivel "privado" (capital humano para sí), el producto de la escuela pública es, consecuentemente, "público" (capital intelectual para el desarrollo común). A pesar de que en ambos tipos de educación hay componentes privatizados y públicos, es ineludible el acento en pos del bien común de la educación pública y el del bien personal en la educación privada.

En concreto, esto significa que la educación pública tiene una responsabilidad en el desarrollo no sólo de los territorios locales (en la mayoría de los cuales, como se ve en este caso, su participación es muy importante), sino que también en el ámbito subnacional. La relevancia del fenómeno de la migración intercomunal de estudiantes da cuenta de la necesidad de una política de la educación pública en el nivel subnacional. Esto permitiría generar mayor eficiencia en la provisión de educación pública en el territorio, impactando en la localización de los establecimientos, en la especialización de éstos de acuerdo al 
tipo de estudiantes y necesidades y hasta en la política de recursos humanos docentes, abriendo más espacios para la generación de carreras docentes y perfeccionamiento.

Esta perspectiva territorial, como cálculo del riesgo de los estudiantes, y como horizonte de acción de la educación pública, debería ser incluida en las últimas propuestas de nueva institucionalidad pública del sistema escolar. Específicamente, en lo que tiene que ver con las iniciativas de asociación entre municipios -lo que se ha denominado "Agencias Locales de Educación" (Panel de Expertos, 2011). Para esto es indispensable comprender la existencia de facto de asociaciones naturales entre municipios que se refieren a territorios ya existentes, que la política pública debería incorporar (como las descritas en torno a Osorno, Puerto Montt y Castro). El funcionamiento actual de estas asociaciones naturales no está regulado, y como tal beneficia en mayor medida a las comunas que actúan como foco de los anillos de migración. Por ejemplo, es dable pensar que estas comunas, que son las que concentran la oferta privada en las regiones, logren suplir los estudiantes que pierden en favor de las escuelas particulares subvencionadas con estudiantes que reciben de las comunas de sus anillos. En este sentido, más allá del nivel de descentralización de la educación pública, es necesario proveer los mecanismos para una administración racional de este tipo de educación, que tienda a la colaboración entre los sistemas de educación pública para el logro de su responsabilidad social en el aseguramiento del derecho a la educación y en el desarrollo territorial equitativo. 


\section{ANEXOS}

\begin{tabular}{|c|c|c|c|c|c|c|c|c|}
\hline & \multicolumn{5}{|c|}{ Estudiantes por dependencia educacional } & \multicolumn{3}{|c|}{ Participación en el sistema escolar } \\
\hline 1981 & 2.215 .973 & 430.232 & 195.521 & 0 & 2.841 .726 & $78,0 \%$ & $15,1 \%$ & $6,9 \%$ \\
\hline 1982 & 2.120 .556 & 553.600 & 144.983 & 0 & 2.819 .139 & $75,2 \%$ & $19,6 \%$ & $5,1 \%$ \\
\hline 1984 & 1.968 .962 & 758.842 & 158.748 & 0 & 2.886 .552 & $68,2 \%$ & $26,3 \%$ & $5,5 \%$ \\
\hline 1985 & 1.936 .295 & 832.455 & 194.660 & 0 & 2.963 .410 & $65,3 \%$ & $28,1 \%$ & $6,6 \%$ \\
\hline 1986 & 1.872 .013 & 913.925 & 182.286 & 0 & 2.967 .864 & $63,1 \%$ & $30,8 \%$ & $6,1 \%$ \\
\hline 1987 & 1.797 .953 & 910.968 & 196.200 & 57.634 & 2.962 .755 & $60,7 \%$ & $32,7 \%$ & $6,6 \%$ \\
\hline 1990 & 1.717 .928 & 963.212 & 235.342 & 57.270 & 2.973 .752 & $57,8 \%$ & $34,3 \%$ & $7,9 \%$ \\
\hline 1991 & 1.699 .700 & 952.973 & 242.791 & 56.398 & 2.951 .862 & $57,6 \%$ & $34,2 \%$ & $8,2 \%$ \\
\hline 1992 & 1.721 .836 & 967.025 & 253.635 & 53.362 & 2.995 .858 & $57,5 \%$ & $34,1 \%$ & $8,5 \%$ \\
\hline 1993 & 1.725 .908 & 977.300 & 265.198 & 51.793 & 3.020 .199 & $57,1 \%$ & $34,1 \%$ & $8,8 \%$ \\
\hline 1994 & 1.745 .179 & 989.250 & 273.351 & 51.093 & 3.058 .873 & $57,1 \%$ & $34,0 \%$ & $8,9 \%$ \\
\hline 1995 & 1.788 .447 & 1.023 .423 & 288.583 & 50.176 & 3.150 .629 & $56,8 \%$ & $34,1 \%$ & $9,2 \%$ \\
\hline 1996 & 1.828 .088 & 1.081 .427 & 309.558 & 52.712 & 3.271 .785 & $55,9 \%$ & $34,7 \%$ & $9,5 \%$ \\
\hline 2001 & 1.889 .645 & 1.302 .010 & 312.928 & 54.439 & 3.559 .022 & $53,1 \%$ & $38,1 \%$ & $8,8 \%$ \\
\hline 2002 & 1.875 .362 & 1.361 .944 & 306.029 & 57.879 & 3.601 .214 & $52,1 \%$ & $39,4 \%$ & $8,5 \%$ \\
\hline 2003 & 1.843 .228 & 1.441 .511 & 287.572 & 56.400 & 3.628 .711 & $50,8 \%$ & $41,3 \%$ & $7,9 \%$ \\
\hline 2004 & 1.795 .369 & 1.510 .134 & 281.140 & 51.774 & 3.638 .417 & $49,3 \%$ & $42,9 \%$ & $7,7 \%$ \\
\hline 2005 & 1.766 .116 & 1.577 .452 & 251.803 & 56.856 & 3.652 .227 & $48,4 \%$ & $44,7 \%$ & $6,9 \%$ \\
\hline 2006 & 1.698 .639 & 1.642 .413 & 248.009 & 56.593 & 3.645 .654 & $46,6 \%$ & $46,6 \%$ & $6,8 \%$ \\
\hline 2007 & 1.625 .971 & 1.681 .315 & 251.426 & 56.050 & 3.614 .762 & $45,0 \%$ & $48,1 \%$ & $7,0 \%$ \\
\hline 2008 & 1.548 .830 & 1.717 .638 & 252.680 & 55.271 & 3.574 .419 & $43,3 \%$ & $49,6 \%$ & $7,1 \%$ \\
\hline
\end{tabular}

Cuadro 1. Evolución de la matrícula y participación por dependencia educacional, Chile 1981 - 2008

Nota: Hasta 1986 la Educación Pública incluye matrícula de dependencia municipal y de dependencia fiscal (debido a la existencia de establecimientos aun no municipalizados). La participación de los establecimientos Particulares Subvencionados incluye Corporaciones. Fuente: MINEDUC (1997) para datos de 1981 a 1989, y MINEDUC (2008) para datos de 1990 a 2008. 


\begin{tabular}{|c|c|c|c|c|c|}
\hline Año & Estrato & $\begin{array}{c}\text { Municipal } \\
\text { (Pública) }\end{array}$ & $\begin{array}{c}\text { Privada } \\
\text { Subvencionada }\end{array}$ & Privada Pagada & Total \\
\hline \multirow{6}{*}{2002} & Bajo & $8 \%$ & $2 \%$ & $0 \%$ & $10 \%$ \\
\hline & Medio Bajo & $26 \%$ & $6 \%$ & $0 \%$ & $31 \%$ \\
\hline & Medio & $18 \%$ & $20 \%$ & $0 \%$ & $37 \%$ \\
\hline & Medio Alto & $2 \%$ & $12 \%$ & $1 \%$ & $15 \%$ \\
\hline & Alto & $0 \%$ & $0 \%$ & $6 \%$ & $7 \%$ \\
\hline & TOTAL & $53 \%$ & $40 \%$ & $7 \%$ & $100 \%$ \\
\hline \multirow{6}{*}{2005} & Bajo & $6 \%$ & $2 \%$ & $0 \%$ & $8 \%$ \\
\hline & Medio Bajo & $23 \%$ & $5 \%$ & $0 \%$ & $28 \%$ \\
\hline & Medio & $18 \%$ & $18 \%$ & $0 \%$ & $37 \%$ \\
\hline & Medio Alto & $2 \%$ & $18 \%$ & $0 \%$ & $20 \%$ \\
\hline & Alto & $0 \%$ & $1 \%$ & $6 \%$ & $7 \%$ \\
\hline & TOTAL & $49 \%$ & $44 \%$ & $6 \%$ & $100 \%$ \\
\hline \multirow{6}{*}{2006} & Bajo & $6 \%$ & $2 \%$ & $0 \%$ & $8 \%$ \\
\hline & Medio Bajo & $23 \%$ & $6 \%$ & $0 \%$ & $29 \%$ \\
\hline & Medio & $17 \%$ & $21 \%$ & $0 \%$ & $37 \%$ \\
\hline & Medio Alto & $2 \%$ & $17 \%$ & $0 \%$ & $18 \%$ \\
\hline & Alto & $0 \%$ & $1 \%$ & $6 \%$ & $7 \%$ \\
\hline & TOTAL & $48 \%$ & $46 \%$ & $7 \%$ & $100 \%$ \\
\hline \multirow{6}{*}{2007} & Bajo & $7 \%$ & $2 \%$ & $0 \%$ & $9 \%$ \\
\hline & Medio Bajo & $24 \%$ & $7 \%$ & $0 \%$ & $30 \%$ \\
\hline & Medio & $14 \%$ & $22 \%$ & $0 \%$ & $36 \%$ \\
\hline & Medio Alto & $1 \%$ & $15 \%$ & $0 \%$ & $17 \%$ \\
\hline & Alto & $0 \%$ & $1 \%$ & $6 \%$ & $7 \%$ \\
\hline & TOTAL & $46 \%$ & $47 \%$ & $7 \%$ & $100 \%$ \\
\hline \multirow{6}{*}{2008} & Bajo & $8 \%$ & $2 \%$ & $0 \%$ & $10 \%$ \\
\hline & Medio Bajo & $23 \%$ & $6 \%$ & $0 \%$ & $29 \%$ \\
\hline & Medio & $13 \%$ & $21 \%$ & $0 \%$ & $34 \%$ \\
\hline & Medio Alto & $2 \%$ & $17 \%$ & $0 \%$ & $19 \%$ \\
\hline & Alto & $0 \%$ & $1 \%$ & $7 \%$ & $8 \%$ \\
\hline & TOTAL & $45 \%$ & $48 \%$ & $7 \%$ & $100 \%$ \\
\hline \multirow{6}{*}{2009} & Bajo & $8 \%$ & $2 \%$ & $0 \%$ & $10 \%$ \\
\hline & Medio Bajo & $23 \%$ & $8 \%$ & $0 \%$ & $31 \%$ \\
\hline & Medio & $11 \%$ & $25 \%$ & $0 \%$ & $36 \%$ \\
\hline & Medio Alto & $1 \%$ & $15 \%$ & $0 \%$ & $16 \%$ \\
\hline & Alto & $0 \%$ & $1 \%$ & $7 \%$ & $8 \%$ \\
\hline & TOTAL & $43 \%$ & $50 \%$ & $7 \%$ & $100 \%$ \\
\hline
\end{tabular}

Cuadro 2. Evolución del nivel socioeconómico (*) de los estudiantes según dependencia educacional, Chile, 2002 - 2009.

(*) De acuerdo a la clasificación por nivel socioeconómico de la prueba SIMCE para $4^{\circ}$ básico. Fuente: Elaboración propia a partir de SIMCE (2009). para datos de 1990 a 2008. 
Estudios Pedagógicos XXXVIII, Nº 2: 35-54, 2012 DISTRIBUCIÓN DESIGUAL DE LAS OPORTUNIDADES EDUCATIVAS EN EL TERRITORIO Y MIGRACIÓN DE...

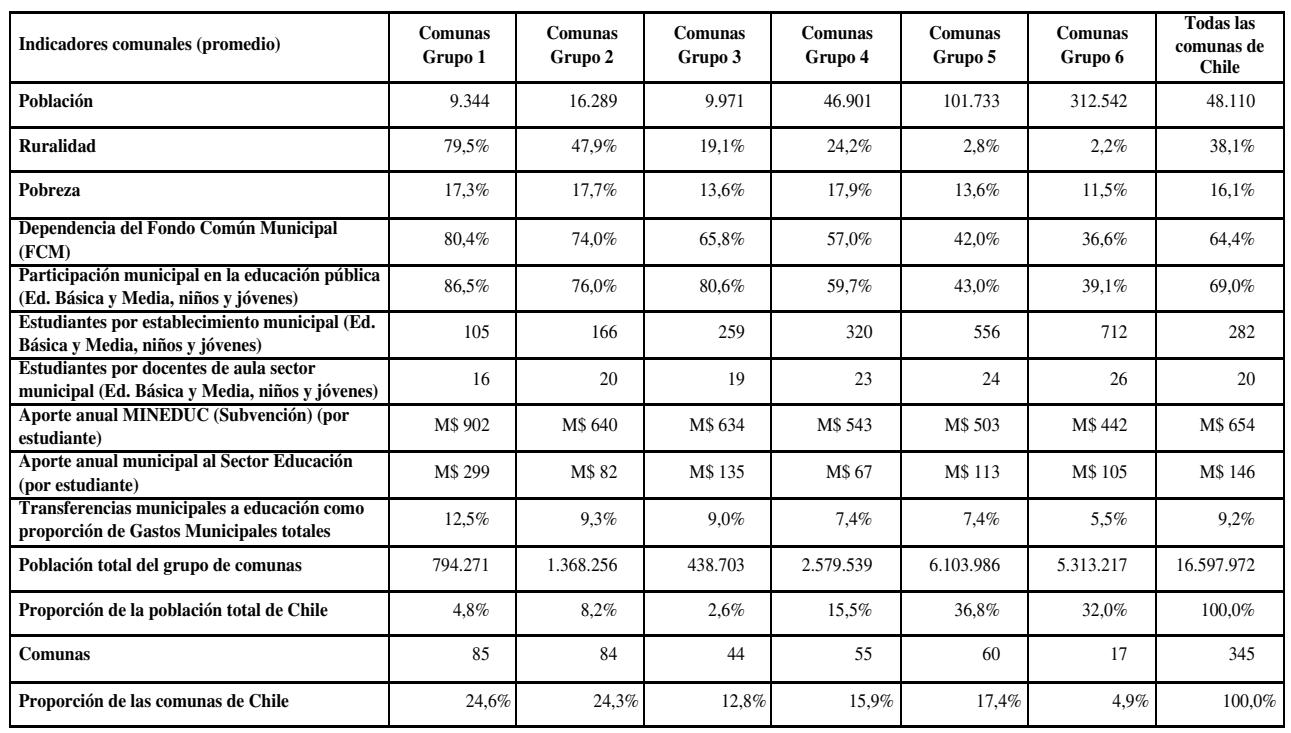

Cuadro 3. Indicadores territoriales y educativos, tipología de comunas de Chile según población y ruralidad, 2007.

Fuente: SINIM 2007, basado en tipología de Donoso \& Arias (2011)

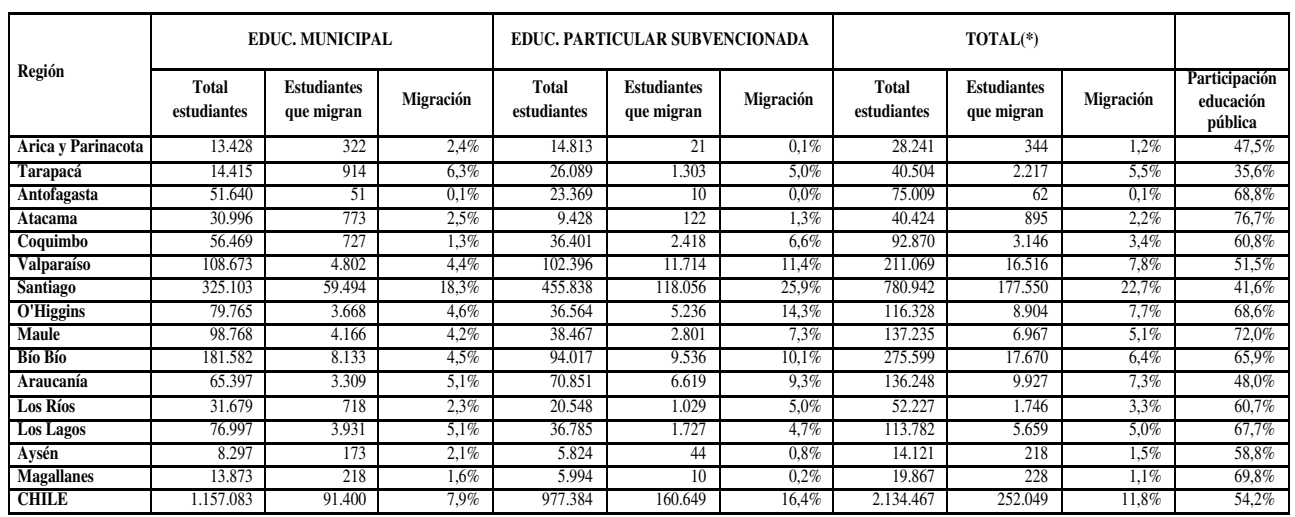

Cuadro 4. Indicadores regionales de migración de estudiantes, Educación Básica, Chile, 2006.

(*) Considera educación municipal y educación particular subvencionada.

Fuente: Elaboración propia a partir de MIDEPLAN (2006), MINEDUC (2007a) y MINEDUC (2007b) 
Estudios Pedagógicos XXXVIII, N² 2: 35-54, 2012

DISTRIBUCIÓN DESIGUAL DE LAS OPORTUNIDADES EDUCATIVAS EN EL TERRITORIO Y MIGRACIÓN DE...

\begin{tabular}{|c|c|c|c|c|c|c|c|c|c|c|}
\hline \multirow{2}{*}{ Región } & \multicolumn{3}{|c|}{ EDUC. MUNICIPAL } & \multicolumn{3}{|c|}{ EDUC. PARTICULAR SUBVENCIONADA } & \multicolumn{3}{|c|}{ TOTAL(*) } & \multirow[b]{2}{*}{$\begin{array}{c}\text { Participación } \\
\text { educación } \\
\text { pública }\end{array}$} \\
\hline & $\begin{array}{c}\text { Total } \\
\text { estudiantes }\end{array}$ & $\begin{array}{l}\text { Estudiantes } \\
\text { que migran }\end{array}$ & Migración & $\begin{array}{c}\text { Total } \\
\text { estudiantes }\end{array}$ & $\begin{array}{l}\text { Estudiantes } \\
\text { que migran }\end{array}$ & Migración & $\begin{array}{c}\text { Total } \\
\text { estudiantes }\end{array}$ & $\begin{array}{l}\text { Estudiantes } \\
\text { que migran }\end{array}$ & Migración & \\
\hline Arica y Parinacota & 7.443 & 56 & $0,8 \%$ & 5.376 & 15 & $0,3 \%$ & 12.819 & 71 & $0,6 \%$ & $58,1 \%$ \\
\hline Tarapacá & 6.549 & 1.061 & $16,2 \%$ & 10.809 & 1.603 & $14,8 \%$ & 17.358 & 2.664 & $15,3 \%$ & $37,7 \%$ \\
\hline Antofagasta & 23.141 & 274 & $1,2 \%$ & 9.198 & 144 & $1,6 \%$ & 32.339 & 418 & $1,3 \%$ & $71,6 \%$ \\
\hline Atacama & 12.179 & 929 & $7,6 \%$ & 7.277 & 447 & $6,1 \%$ & 19.455 & 1.376 & $7,1 \%$ & $62,6 \%$ \\
\hline Coquimbo & 24.313 & 3.104 & $12,8 \%$ & 18.956 & 3.633 & $19,2 \%$ & 43.269 & 6.737 & $15,6 \%$ & $56,2 \%$ \\
\hline Valparaíso & 45.612 & 9.828 & $21,5 \%$ & 53.101 & 13.358 & $25,2 \%$ & 98.714 & 23.187 & $23,5 \%$ & $46,2 \%$ \\
\hline Santiago & 112.688 & 54.217 & $48,1 \%$ & 260.511 & 135.203 & $51,9 \%$ & 373.199 & 189.420 & $50,8 \%$ & $30,2 \%$ \\
\hline O'Higgins & 32.188 & 7.208 & $22,4 \%$ & 20.701 & 7.097 & $34,3 \%$ & 52.888 & 14.305 & $27,0 \%$ & $60,9 \%$ \\
\hline Maule & 39.029 & 8.020 & $20,5 \%$ & 26.629 & 6.940 & $26,1 \%$ & 65.658 & 14.959 & $22,8 \%$ & $59,4 \%$ \\
\hline Bío Bío & 77.827 & 13.345 & $17,1 \%$ & 52.755 & 16.840 & $31,9 \%$ & 130.582 & 30.186 & $23,1 \%$ & $59,6 \%$ \\
\hline Araucanía & 30.495 & 7.004 & $23,0 \%$ & 34.274 & 9.985 & $29,1 \%$ & 64.770 & 16.988 & $26,2 \%$ & $47,1 \%$ \\
\hline Los Ríos & 15.546 & 1.788 & $11,5 \%$ & 10.019 & 2.944 & $29,4 \%$ & 25.564 & 4.731 & $18,5 \%$ & $60,8 \%$ \\
\hline Los Lagos & 30.382 & 4.156 & $13,7 \%$ & 17.955 & 4.633 & $25,8 \%$ & 48.337 & 8.789 & $18,2 \%$ & $62,9 \%$ \\
\hline Aysén & 2.783 & 67 & $2,4 \%$ & 3.683 & 160 & $4,4 \%$ & 6.466 & 227 & $3,5 \%$ & $43,0 \%$ \\
\hline Magallanes & 6.059 & 24 & $0,4 \%$ & 3.513 & 11 & $0,3 \%$ & 9.572 & 35 & $0,4 \%$ & $63,3 \%$ \\
\hline CHILE & 466.233 & 111.081 & $23,8 \%$ & 534.756 & 203.012 & $38,0 \%$ & 1.000 .989 & 314.093 & $31,4 \%$ & $46,6 \%$ \\
\hline
\end{tabular}

Cuadro 5. Indicadores regionales de migración de estudiantes, Educación Media, Chile, 2006.

(*) Considera educación municipal y educación particular subvencionada.

Fuente: Elaboración propia a partir de MIDEPLAN (2006), MINEDUC (2007a) y MINEDUC (2007b)

\begin{tabular}{|l|r|r|r|r|r|r|}
\hline & $\begin{array}{c}\text { Población } \\
\text { regional }\end{array}$ & $\begin{array}{c}\text { Densidad } \\
\text { poblacional } \\
\text { (hab/km²) }\end{array}$ & $\begin{array}{c}\text { Proporción de } \\
\text { la población } \\
\text { nacional }\end{array}$ & $\begin{array}{c}\text { Población que } \\
\text { vive en la } \\
\text { capital regional }\end{array}$ & $\begin{array}{c}\text { Población que } \\
\text { vive en } \\
\text { capitales } \\
\text { provinciales y } \\
\text { regionales }\end{array}$ & Población rural \\
\hline Arica y Parinacota & 188.524 & 11,2 & $1,1 \%$ & $97,8 \%$ & $98,5 \%$ & $8,5 \%$ \\
\hline Tarapacá & 293.205 & 6,9 & $1,8 \%$ & $62,3 \%$ & $67,4 \%$ & $6,2 \%$ \\
\hline Antofagasta & 554.773 & 4,4 & $3,3 \%$ & $62,8 \%$ & $93,3 \%$ & $2,4 \%$ \\
\hline Atacama & 274.436 & 3,7 & $1,7 \%$ & $55,5 \%$ & $77,6 \%$ & $9,0 \%$ \\
\hline Coquimbo & 687.659 & 17,0 & $4,1 \%$ & $28,4 \%$ & $48,7 \%$ & $20,2 \%$ \\
\hline Valparaíso & 1.701 .293 & 103,8 & $10,3 \%$ & $16,2 \%$ & $37,6 \%$ & $8,5 \%$ \\
\hline Santiago & 6.676 .745 & 433,5 & $40,2 \%$ & $2,7 \%$ & $20,9 \%$ & $3,1 \%$ \\
\hline O'Higgins & 857.677 & 52,3 & $5,2 \%$ & $27,7 \%$ & $37,5 \%$ & $29,3 \%$ \\
\hline Maule & 983.396 & 32,5 & $5,9 \%$ & $23,5 \%$ & $50,5 \%$ & $33,1 \%$ \\
\hline Bío Bío & 1.996 .099 & 53,9 & $12,0 \%$ & $11,3 \%$ & $30,8 \%$ & $16,9 \%$ \\
\hline Araucanía & 945.544 & 29,7 & $5,7 \%$ & $30,4 \%$ & $35,8 \%$ & $32,1 \%$ \\
\hline Los Ríos & 375.193 & 20,4 & $2,3 \%$ & $41,4 \%$ & $51,9 \%$ & $31,1 \%$ \\
\hline Los Lagos & 804.975 & 16,6 & $4,8 \%$ & $27,2 \%$ & $53,9 \%$ & $30,3 \%$ \\
\hline Aysén & 101.523 & 0,9 & $0,6 \%$ & $55,2 \%$ & $87,9 \%$ & $16,7 \%$ \\
\hline Magallanes & 156.930 & 1,2 & $0,9 \%$ & $79,0 \%$ & $97,3 \%$ & $7,1 \%$ \\
\hline CHILE & 16.597 .972 & 22,0 & $100,0 \%$ & $18,4 \%$ & $36,9 \%$ & $13,1 \%$ \\
\hline
\end{tabular}

Cuadro 6. Diversidad de poblamiento de las regiones de Chile (2007)

Fuente: SINIM (2007). 


\begin{tabular}{|c|c|c|c|c|c|c|c|c|}
\hline & Municipal & $\begin{array}{c}\text { Particular } \\
\text { Subvencionado(*) }\end{array}$ & $\begin{array}{c}\text { Particular } \\
\text { Pagado }\end{array}$ & $\begin{array}{l}\text { Proporción del total de los } \\
\text { estudiantes del país }\end{array}$ & $\begin{array}{c}\text { Estudiantes que } \\
\text { aporta al sistema } \\
\text { municipal }\end{array}$ & $\begin{array}{c}\text { Estudiantes que } \\
\text { aporta al } \\
\text { sistema } \\
\text { particular } \\
\text { subvencionado }\end{array}$ & $\begin{array}{c}\text { Estudiantes que } \\
\text { aporta al } \\
\text { sistema } \\
\text { particular } \\
\text { pagado }\end{array}$ & $\begin{array}{l}\text { Participación } \\
\text { educación } \\
\text { pública en la } \\
\text { región }\end{array}$ \\
\hline Arica y Parinacota & 19.844 & 20.580 & 1.258 & $1,3 \%$ & $1,3 \%$ & $1,3 \%$ & $0,6 \%$ & $47,6 \%$ \\
\hline Tarapacá & 19.600 & 38.201 & 894 & $1,8 \%$ & $1,3 \%$ & $2,5 \%$ & $0,4 \%$ & $33,4 \%$ \\
\hline Antofagasta & 72.271 & 32.992 & 8.036 & $3,4 \%$ & $4,6 \%$ & $2,2 \%$ & $3,7 \%$ & $63,8 \%$ \\
\hline Atacama & 41.241 & 17.367 & 1.584 & $1,8 \%$ & $2,7 \%$ & $1,1 \%$ & $0,7 \%$ & $68,5 \%$ \\
\hline Coquimbo & 76.454 & 58.560 & 3.369 & $4,2 \%$ & $4,9 \%$ & $3,8 \%$ & $1,6 \%$ & $55,2 \%$ \\
\hline Valparaíso & 146.247 & 156.642 & 22.783 & $9,9 \%$ & $9,4 \%$ & $10,2 \%$ & $10,6 \%$ & $44,9 \%$ \\
\hline Santiago & 420.826 & 713.546 & 132.299 & $38,4 \%$ & $27,1 \%$ & $46,6 \%$ & $61,3 \%$ & $33,2 \%$ \\
\hline O'Higgins & 108.853 & 58.489 & 8.286 & $5,3 \%$ & $7,0 \%$ & $3,8 \%$ & $3,8 \%$ & $62,0 \%$ \\
\hline Maule & 131.918 & 67.954 & 6.178 & $6,2 \%$ & $8,5 \%$ & $4,4 \%$ & $2,9 \%$ & $64,0 \%$ \\
\hline Bío Bío & 247.584 & 152.138 & 15.369 & $12,6 \%$ & $15,9 \%$ & $9,9 \%$ & $7,1 \%$ & $59,6 \%$ \\
\hline Araucanía & 91.621 & 105.597 & 4.642 & $6,1 \%$ & $5,9 \%$ & $6,9 \%$ & $2,1 \%$ & $45,4 \%$ \\
\hline Los Ríos & 44.878 & 31.858 & 1.953 & $2,4 \%$ & $2,9 \%$ & $2,1 \%$ & $0,9 \%$ & $57,0 \%$ \\
\hline Los Lagos & 102.703 & 58.686 & 7.229 & $5,1 \%$ & $6,6 \%$ & $3,8 \%$ & $3,3 \%$ & $60,9 \%$ \\
\hline Aysén & 11.256 & 9.501 & 0 & $0,6 \%$ & $0,7 \%$ & $0,6 \%$ & $0,0 \%$ & $54,2 \%$ \\
\hline $\begin{array}{c}\text { Magallanes } \\
\end{array}$ & 19.239 & 9.572 & 2.071 & $0,9 \%$ & $1,2 \%$ & $0,6 \%$ & $1,0 \%$ & $62,3 \%$ \\
\hline $\begin{array}{l}\text { REGIONES ALTA } \\
\text { MIGRACIÓN }\end{array}$ & 420.826 & 713.546 & 132.299 & $38,4 \%$ & $27,1 \%$ & $46,6 \%$ & $61,3 \%$ & $33,2 \%$ \\
\hline $\begin{array}{l}\text { REGIONES MIGRACION } \\
\text { INTERMEDIA }\end{array}$ & 950.258 & 689.924 & 69.809 & $51,8 \%$ & $61,1 \%$ & $45,0 \%$ & $32,3 \%$ & $55,6 \%$ \\
\hline REGIONES MIGRACION & & & & & & & & \\
\hline ESCASA & 183.451 & 128.213 & 13.843 & $9,9 \%$ & $11,8 \%$ & $8,4 \%$ & $6,4 \%$ & $56,4 \%$ \\
\hline CHILE & 1.554 .535 & 1.531 .683 & 215.951 & $100,0 \%$ & $100,0 \%$ & $100,0 \%$ & $100,0 \%$ & $47,1 \%$ \\
\hline
\end{tabular}

Cuadro 7. Distribución de matrícula, dependencia educacional y regiones, Educación Básica y Media de niños y jóvenes, Chile, 2007

(*) Incluye corporaciones privadas o de administración delegada. Fuente: MINEDUC (2007b)

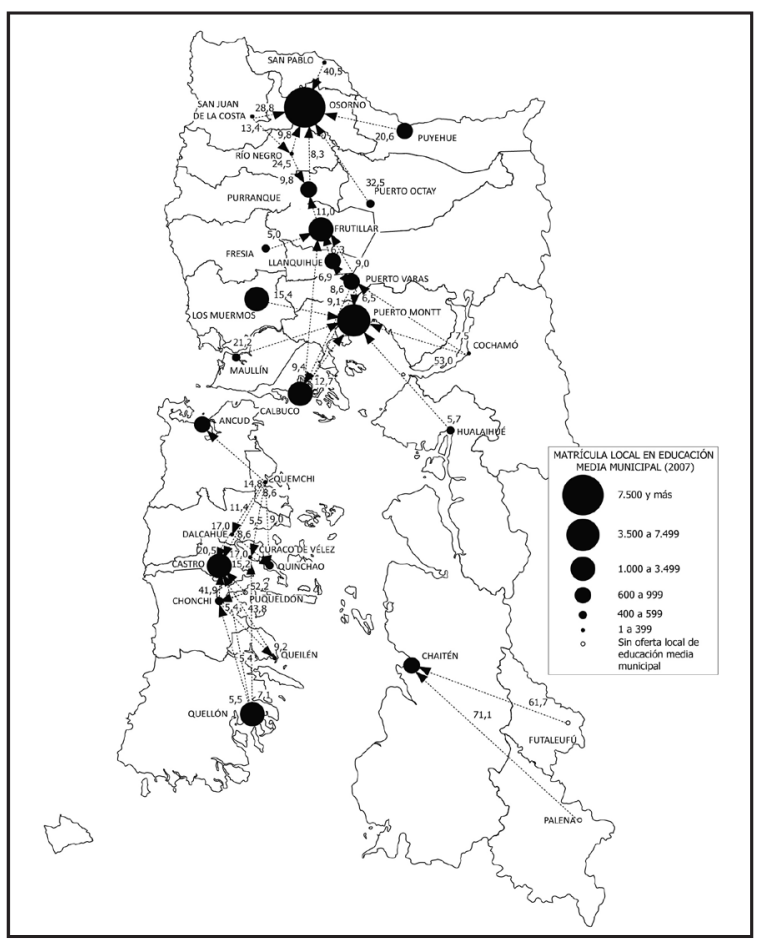

Figura 1. Proporción de estudiantes que migran a otras comunas, Educación Media Municipal, 2006-2007

Nota: Los valores representan la proporción de personas que viven en la comuna (nodo de origen) y migran a la comuna indicada con la flecha (nodo de destino) Se presentan las relaciones mayores a 4,9\%. El tamaño de los nodos es proporcional a la cantidad de estudiantes de educación media municipal de cada comuna.

Fuente: Elaboración propia a partir de MIDEPLAN (2006), MINEDUC (2007a) y MINEDUC (2007b) 


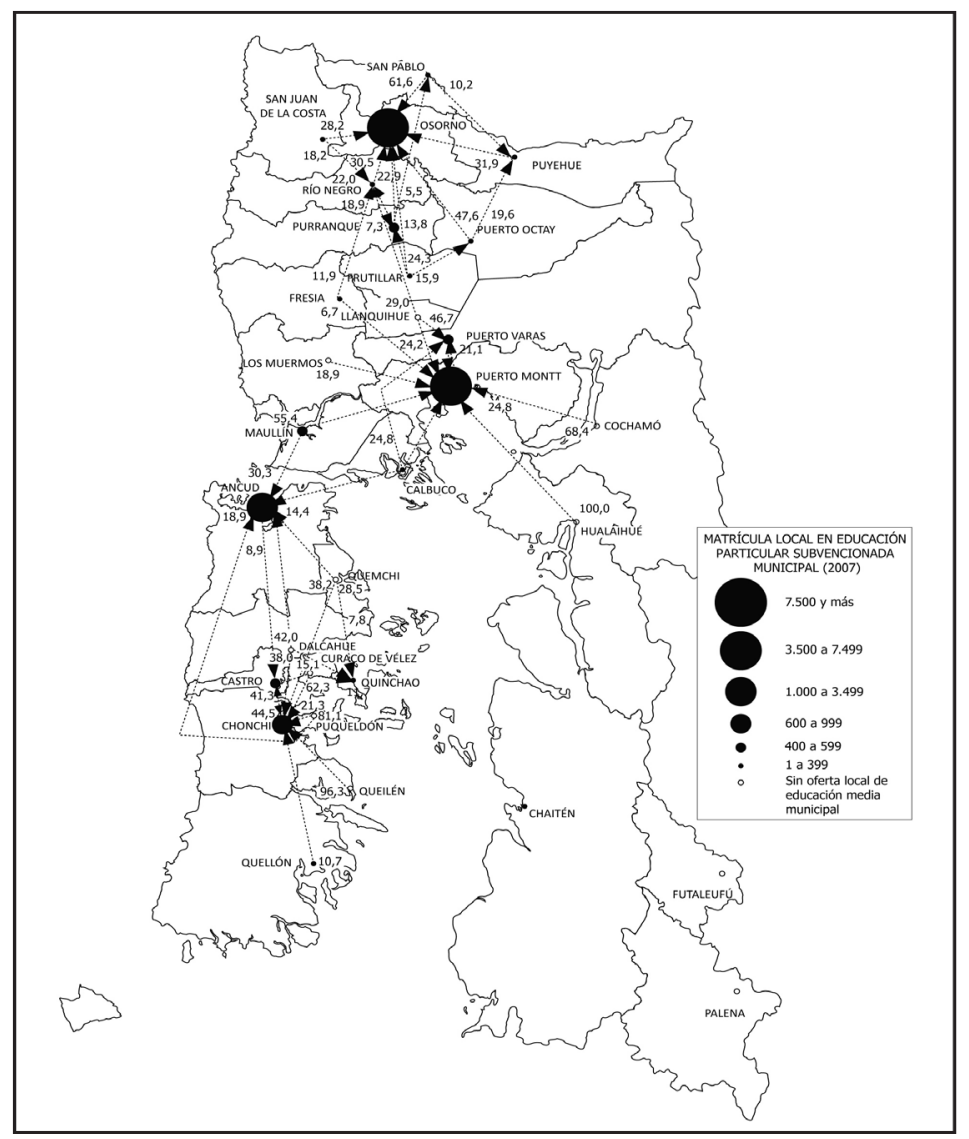

Figura 2. Proporción de estudiantes que migran a otras comunas, Educación Media Particular Subvencionada, 2006-2007.

Nota: Los valores representan la proporción de personas que viven en la comuna (nodo de origen) y migran a la comuna indicada con la flecha (nodo de destino) Se presentan las relaciones mayores a 4,9\%. El tamaño de los nodos es proporcional a la cantidad de estudiantes de educación media municipal de cada comuna.

Fuente: Elaboración propia a partir de MIDEPLAN (2006), MINEDUC (2007a) y MINEDUC (2007b) 


\begin{tabular}{|c|c|c|c|c|c|c|c|c|c|}
\hline Comuna & Población & Ruralidad & $\begin{array}{l}\text { Distancia a } \\
\text { Puerto Montt } \\
\quad(\mathbf{k m})\end{array}$ & $\begin{array}{c}\text { Dependencia } \\
\text { FCM sobre } \\
\text { ingresos propios }\end{array}$ & Pobreza & $\begin{array}{l}\text { Estudiantes en } \\
\text { E. Media } \\
\text { (Municipal) }\end{array}$ & $\begin{array}{l}\text { Migración de } \\
\text { estudiantes }\end{array}$ & $\begin{array}{l}\text { Impacto local de } \\
\text { la captación de } \\
\text { estudiantes }\end{array}$ & $\begin{array}{l}\text { Participación } \\
\text { municipal } \\
\text { (educación } \\
\text { media) }\end{array}$ \\
\hline Puerto Montt & 219.164 & 12,4 & & 19,3 & 9,6 & 7.299 & 6,9 & 11,1 & 53,7 \\
\hline Puerto Varas & 38.152 & 27,3 & 21,2 & 22,7 & 9,0 & 890 & 40,7 & 7,1 & 41,6 \\
\hline Llanquihue & 17.864 & 20,0 & 25,4 & 54,0 & 10,9 & 745 & 17,4 & 15,0 & 100,0 \\
\hline Frutillar & 17.358 & 32,6 & 42,0 & 59,5 & 8,2 & 1.152 & 16,8 & 37,9 & 88,5 \\
\hline Los Muermos & 16.686 & 59,9 & 48,5 & 78,3 & 8,9 & 1.297 & 8,2 & 45,5 & 70,2 \\
\hline Calbuco & 34.229 & 64,1 & 53,9 & 66,1 & 10,5 & 1.492 & 28,5 & 9,2 & 78,7 \\
\hline Fresia & 12.607 & 53,3 & 66,3 & 77,2 & 9,9 & 416 & 16,1 & 0,0 & 69,4 \\
\hline Maullín & 14.355 & 56,0 & 72,4 & 87,5 & 9,1 & 438 & 38,4 & 6,6 & 100,0 \\
\hline Hualaihué & 8.439 & 54,2 & 109,0 & 86,3 & 4,3 & 562 & 7,1 & 1,8 & 100,0 \\
\hline Cochamó & 4.356 & 100,0 & 131,5 & 65,4 & 5,5 & 116 & 52,1 & 0,0 & 100,0 \\
\hline
\end{tabular}

Cuadro 8. Características territoriales y de migración, Educación Media Municipal, comunas del anillo de Puerto Montt, Los Lagos, 2006 - 2007.

Fuente: Elaboración propia a partir de MIDEPLAN (2006), MINEDUC (2007a), MINEDUC (2007b) y SINIM (2007)

\begin{tabular}{|c|c|c|c|c|c|c|c|c|c|}
\hline Comuna & Población & Ruralidad & $\begin{array}{c}\text { Distancia a } \\
\text { Osorno } \\
(\mathbf{k m})\end{array}$ & $\begin{array}{c}\text { Dependencia } \\
\text { FCM sobre } \\
\text { ingresos propios }\end{array}$ & Pobreza & $\begin{array}{l}\text { Estudiantes en } \\
\text { E. Media } \\
\text { (Municipal) }\end{array}$ & $\begin{array}{l}\text { Migración de } \\
\text { estudiantes }\end{array}$ & $\begin{array}{c}\text { Impacto local de } \\
\text { la captación de } \\
\text { estudiantes }\end{array}$ & $\begin{array}{l}\text { Participación } \\
\text { municipal } \\
\text { (educación } \\
\text { media) }\end{array}$ \\
\hline Osorno & 159.057 & 10,2 & & 25,1 & 19,5 & 9.186 & 2,3 & 11,3 & 49,9 \\
\hline San Pablo & 9.410 & 66,4 & 24,4 & 64,6 & 14,1 & 311 & 52,4 & 43,4 & 65,9 \\
\hline San Juan de la Costa & 8.217 & 88,3 & 32,6 & 94,8 & 14,3 & 112 & 52,3 & 0,0 & 50,7 \\
\hline Río Negro & 13.786 & 60,7 & 35,4 & 70,1 & 16,1 & 311 & 50,9 & 6,1 & 29,0 \\
\hline Purranque & 20.855 & 38,3 & 41,5 & 58,5 & 20,3 & 838 & 13,8 & 17,1 & 54,5 \\
\hline Puyehue & 11.427 & 71,8 & 49,5 & 53,0 & 14,2 & 699 & 21,7 & 31,9 & 44,5 \\
\hline Puerto Octay & 9.724 & 67,3 & 53,5 & 62,6 & 12,0 & 492 & 40,0 & 43,3 & 67,3 \\
\hline
\end{tabular}

Cuadro 9. Características territoriales y de migración, Educación Media Municipal, comunas del anillo de Osorno, Los Lagos, 2006 - 2007.

Fuente: Elaboración propia a partir de MIDEPLAN (2006), MINEDUC (2007a), MINEDUC (2007b) y SINIM (2007).

\begin{tabular}{|c|c|c|c|c|c|c|c|c|}
\hline & \multicolumn{2}{|c|}{ Educación municipal } & \multicolumn{6}{|c|}{ Proporción de estudiantes según estrato socioeconómico SIMCE } \\
\hline & Media & DE & $\mathbf{A}$ & B & $\mathrm{C}$ & D & $\mathbf{E}$ & Total \\
\hline Puerto Montt & 243 & 58,6 & $25,1 \%$ & $49,2 \%$ & $25,8 \%$ & $0,0 \%$ & $0,0 \%$ & $100,0 \%$ \\
\hline Puerto Varas & 228 & 50,1 & $0,0 \%$ & $100,0 \%$ & $0,0 \%$ & $0,0 \%$ & $0,0 \%$ & $100,0 \%$ \\
\hline Llanquihue & 219 & 51,1 & $0,0 \%$ & $100,0 \%$ & $0,0 \%$ & $0,0 \%$ & $0,0 \%$ & $100,0 \%$ \\
\hline Frutillar & 275 & 56,9 & $52,2 \%$ & $47,8 \%$ & $0,0 \%$ & $0,0 \%$ & $0,0 \%$ & $100,0 \%$ \\
\hline Los Muermos & 212 & 47,3 & $100,0 \%$ & $0,0 \%$ & $0,0 \%$ & $0,0 \%$ & $0,0 \%$ & $100,0 \%$ \\
\hline Calbuco & 240 & 57,4 & $100,0 \%$ & $0,0 \%$ & $0,0 \%$ & $0,0 \%$ & $0,0 \%$ & $100,0 \%$ \\
\hline Fresia & 220 & 53,9 & $100,0 \%$ & $0,0 \%$ & $0,0 \%$ & $0,0 \%$ & $0,0 \%$ & $100,0 \%$ \\
\hline Maullín & 220 & 52,5 & $100,0 \%$ & $0,0 \%$ & $0,0 \%$ & $0,0 \%$ & $0,0 \%$ & $100,0 \%$ \\
\hline Hualaihué & 238 & 54,9 & $100,0 \%$ & $0,0 \%$ & $0,0 \%$ & $0,0 \%$ & $0,0 \%$ & $100,0 \%$ \\
\hline Cochamó & 204 & 48,4 & $100,0 \%$ & $0,0 \%$ & $0,0 \%$ & $0,0 \%$ & $0,0 \%$ & $100,0 \%$ \\
\hline
\end{tabular}

Cuadro 10. Resultados SIMCE Matemáticas $2^{\circ}$ Medio y composición socioeconómica de quienes rinden la prueba, Educación Municipal, comunas del anillo en torno a Puerto Montt, 2006.

Fuente: Resultados SIMCE 2006

\begin{tabular}{|l|c|c|c|c|c|c|c|c|}
\hline & \multicolumn{2}{|c|}{ Educación municipal } & \multicolumn{5}{|c|}{ Proporción de estudiantes según estrato socioeconómico SIMCE } \\
\hline & Media & DE & A & B & C & D & Total \\
\hline Osorno & 253 & 56,9 & $28,1 \%$ & $48,5 \%$ & $23,4 \%$ & $0,0 \%$ & $0,0 \%$ & $100,0 \%$ \\
\hline San Pablo & 230 & 55,0 & $100,0 \%$ & $0,0 \%$ & $0,0 \%$ & $0,0 \%$ & $0,0 \%$ & $100,0 \%$ \\
\hline San Juan de la Costa & 209 & 43,6 & $100,0 \%$ & $0,0 \%$ & $0,0 \%$ & $0,0 \%$ & $0,0 \%$ & $100,0 \%$ \\
\hline Río Negro & 215 & 48,4 & $100,0 \%$ & $0,0 \%$ & $0,0 \%$ & $0,0 \%$ & $0,0 \%$ & $100,0 \%$ \\
\hline Purranque & 251 & 52,0 & $100,0 \%$ & $0,0 \%$ & $0,0 \%$ & $0,0 \%$ & $0,0 \%$ & $100,0 \%$ \\
\hline Puyehue & 206 & 45,3 & $100,0 \%$ & $0,0 \%$ & $0,0 \%$ & $0,0 \%$ & $0,0 \%$ & $100,0 \%$ \\
\hline Puerto Octay & 232 & 53,8 & $100,0 \%$ & $0,0 \%$ & $0,0 \%$ & $0,0 \%$ & $0,0 \%$ & $100,0 \%$ \\
\hline
\end{tabular}

Cuadro 11. Resultados SIMCE Matemáticas $2^{\circ}$ Medio y composición socioeconómica de quienes rinden la prueba, Educación Municipal, comunas del anillo en torno a Osorno, 2006.

Fuente: Resultados SIMCE 2006 


\section{REFERENCIAS BIBLIOGRÁFICAS}

Gobierno de Chile (2008). Ley 20.248 de Subvención Escolar Preferencial, promulgada el 25 de enero de 2008. Disponible en: http://www.leychile.cl/Navegar?idNorma=269001ybuscar=1 ey+20248 (Consultado el 14 de abril de 2011)

Chumacero, R.; Gómez, D.; Y Paredes, R. (2008). I Would Walk 500 Miles (if it paid). Mimeo, Pontificia Universidad Católica de Chile. Disponible en http://mpra.ub.uni-muenchen.de/15125/1/ MPRA_paper_15125.pdf (Consultado el 15 de abril de 2011)

Cuevas, A. Y Vázquez, V. (2009). Migración internacional, remesas y cambios en la estructura territorial de la economía en el municipio de Cerritos, San Luis Potosí, México. Revista de Geografía Norte Grande, n.42, pp. 5-20.

Donoso, S. (2006) Financiamiento y gestión de la educación pública chilena de los años 90. Cadernos de Pesquisa, v. 36, n. 127, pp. 151-172, jan./abr.

Donoso, S. y Arias, Ó. (2011). Diferencias de escala en los sistemas locales de educación pública en Chile. Ensaio, v. 19, n. 71, pp. 283-306.

Hsieh, Ch. y Urquiola, M. (2006). The effects of generalized school choice on achievement and stratification: Evidence from Chile's voucher program. Journal of Public Economics, v.90, pp. $1477-1503$

López, N. y Tedesco, J. C. (2002). Las condiciones de educabilidad de los niños y adolescentes en América Latina. Buenos Aires: IIPE.

MIDEPLAN (2006). Encuesta de Caracterización Socioeconómica Nacional (CASEN). Chile: Ministerio de Planificación y Cooperación.

MINEDUC (1997). Compendio de información estadística. Chile: Ministerio de Educación.

MINEDUC (2007a). Tabla de directorio de establecimientos. Chile: Ministerio de Educación.

MINEDUC (2007b). Tabla de matrícula. Chile: Ministerio de Educación.

MINEDUC (2008). La educación en cifras. Chile: Ministerio de Educación.

Oliva, M. A. (2008). Política educativa y profundización de la desigualdad en Chile. Estudios pedagógicos, vol.34, n.2, pp. 207-226.

PANEL DE EXPERTOS PARA UNA EDUCACIÓN DE CALIDAD (2011). Informe Final: Segunda Etapa - Fortalecimiento de la Institucionalidad Pública. Disponible en http://www.mineduc. cl/usuarios/mineduc/doc/201103291620330.INFORMEFINALPANELDEEXPERTOS1.pdf (Consultado el 15 de abril de 2011).

Redondo, J. M. (2005). El experimento chileno en educación: ¿conduce a mayor equidad y calidad en la educación? Última década, vol.13, n.22, pp. 95-110.

Rodríguez, J. Y González, D. (2006). Redistribución de la población y migración interna en Chile: continuidad y cambio según los últimos cuatro censos nacionales de población y vivienda. Revista de Geografía Norte Grande, n.35, pp. 7-28.

Sapelli, C. (2002). La economía de la educación y el sistema educativo chileno. Cuadernos de Economía, a. 39, n. 118, pp. 281-296.

SIMCE (2009). Sistema de Medición de Calidad de la Educación, Carpetas de Prensa 2002-2009, Ministerio de Educación, Chile. Disponible en: http://www.simce.cl/index.php. (Consultado el 22 de marzo de 2011).

SINIM (2007). Sistema Nacional de Información Municipal, Subsecretaria de Desarrollo Regional y Administrativo. Chile: Ministerio del Interior. 